\title{
Differential Factors of Contraceptive Use and Adverse Outcomes of Pregnancy in Women with Ages 15 to 49 in Pretoria, South Africa
}

\author{
Zeleke Worku \\ Tshwane University of Technology Business School, Pretoria, South Africa \\ Email: WorkuZ@tut.ac.za
}

Received December 15, 2013; revised January 12, 2014; accepted February 7, 2014

Copyright (C) 2014 Zeleke Worku. This is an open access article distributed under the Creative Commons Attribution License, which permits unrestricted use, distribution, and reproduction in any medium, provided the original work is properly cited. In accordance of the Creative Commons Attribution License all Copyrights (C) 2014 are reserved for SCIRP and the owner of the intellectual property Zeleke Worku. All Copyright (C) 2014 are guarded by law and by SCIRP as a guardian.

\begin{abstract}
Challenges of teenage pregnancy and adverse outcomes of pregnancy constitute a major public health problem in South African women of the childbearing age of 15 to 49 years. This is a 6-year long study that was conducted in Pretoria, South Africa in order to identify factors that affect utilization of modern contraceptives and adverse pregnancy outcomes in women of the childbearing age of 15 to 49 years. Data analysis was conducted by using two-by-two Pearson's chi-square tests of associations, binary logistic regression analysis, survival analysis, and multilevel analysis. The study showed that the percentage of women who regularly used modern family planning methods such as condoms, pills, injections, intra-uterine devices and sterilization was $\mathbf{4 1 . 7 4 \%}$. The average ages of women at first sex and pregnancy were 18.72 and 19.36 years respectively. Adverse outcomes of pregnancy occurred in 12.19\% of women. Based on Odds Ratios (OR) estimated from binary logistic regression analysis, utilization of contraceptives was significantly influenced by easy access to family planning services, level of support from sexual partner, and young age at first pregnancy. Based on Hazard Ratios (HR) estimated from the Cox Proportional Hazards Model, the occurrence of adverse outcomes of pregnancy was significantly influenced by easy access to family planning services, unwanted pregnancy, and young age at first pregnancy. Women who experienced adverse outcomes of pregnancy were characterized by poor utilization of reproductive health and modern family planning services. There was a significant difference among the $\mathbf{2 0}$ health service delivery wards and 11 health service facilities in which reproductive health services were delivered to women with regards to the quality of service delivery.
\end{abstract}

\section{KEYWORDS}

Contraceptive Use; Adverse Outcomes; Odds Ratio; Hazard Ratio; Multilevel Analysis

\section{Introduction}

Objectives and background of study: the aim of the study is to describe the socio-demographic and reproductive characteristics of women who underutilize contraceptives and experience adverse outcomes of pregnancy in and around Pretoria, South Africa. The study had four specific objectives: to identify and quantify factors that affect the degree of utilization of modern contraceptives by women in the childbearing age of 15 to 49 years living in Pretoria, South Africa; to identify and quantify factors that affect the occurrence of adverse outcomes of pregnancy in women; and to find out if women who experienced adverse outcomes of pregnancy failed to effectively utilize reproductive health and modern family planning services that were provided to them by the Health Department of the City of Tshwane Metropolitan Municipality (CTMM). The study will also assess the degree of variability among 20 service delivery wards and 11 health facilities with regards to utilization of modern contraceptives and Family Planning (FP) services that were provided to women. This study was based on data collected from a random sample of 8497 women aged 15 to 49 years living in and around the City of Pre- 
toria between 2004 and 2009 as a part of a 6-year-long follow-up study conducted by the CTMM. Data were collected from the 8497 women who took part in the study on several socio-economic, demographic, healthrelated and family planning variables. The City of Pretoria is a part of the CTMM, and is the capital city of South Africa. The research work was motivated by the following key reasons: the lack of reliable scientific studies on the reproductive needs and requirements of the general population, the lack of awareness about family planning services provided by the CTMM, poor utilization of family planning services provided by the CTMM at the various service centers, and a high level of adverse outcomes of pregnancy among women in the childbearing age of 15 to 49 years living in and around Pretoria, especially among poor black women residing in townships. The study aims to show that the majority of women who have experienced adverse outcomes of pregnancy did not utilize modern family planning services effectively. The study aims to identify and quantify factors that were responsible for underutilization of modern family planning services in women who have experienced adverse outcomes of pregnancy.

Literature review: the Health Department of the CTMM is responsible for providing reproductive health services including modern family planning services and contraceptives to women in the childbearing age of 15 to 49 years who live in and around Pretoria. According to the City of Tshwane Metropolitan Municipality ([1], 2012: 14-19), reproductive health services that are provided to the general public have been underutilized. The South African national survey conducted on 15 - 24 years old by MacPhail, Pettifor, Pascoe \& Rees ([2], 2007: 44-53) has found that $52.2 \%$ of South African women aged 15 to 24 years utilize modern contraceptives, and that there was a statistically significant association between contraceptive use and the employment status of women. Before April 1994, reproductive health and modern family planning services were not affordable to unemployed and poor black South African women ([3], 1998: 180-183). The White Paper on the Population Policy of South Africa (South African Government Communication and Information System ([4], 1998)) was designed in order to redress inequities of the past by promoting access to such services among adolescents and youth as a means of reducing the incidence of high-risk teenage pregnancies, abortion and sexually transmitted diseases including HIV and AIDS through the provision of life skills, sexuality and gender-sensitive education, user-friendly health services and opportunities for engaging in social and community life. The following types of adverse outcomes of pregnancy (Hayes [5], 2012) are common among women in the childbearing age of 15 to 49 years who live in Pretoria: miscarriage, still birth, criminal abortions performed by teenagers who wish to get rid of unwanted pregnancies, pre-term delivery, malformation in the fetus, low birth weight, severe harm to the fetus or mother due to miscarriage, the loss of the fetus, the loss of the mother, permanent body organ damage, infertility, pre-term birth, intrauterine growth restriction, or lifelong illness arising from pre-term delivery. Abortions have been legalized in South Africa since 1997 (South African Government Communication and Information System, [6], 1996). The 1996 Act on the Choice on Termination of Pregnancy allows abortions on demand up to 20 weeks' gestation. The study conducted by Jewkes, Brown, Dickson-Tetteh, Levin and Rees [7] (2002: 1252-1263) has found that legal abortions with an average of 40,000 are performed in South Africa annually. The study by Seutlwadi, Peltzer, Mchunu and Tutshana [8] (2012: 43-47) has found that utilization of contraceptives among young women aged 18 to 24 years was low $(9.3 \%$ were using the Pill, $5.2 \%$ the intra-uterine contraceptive device, $25.6 \%$ injectables, $57.6 \%$ male condoms, $5.9 \%$ female condoms, and $8.9 \%$ dual methods; other methods used were the rhythm method (7.0\%), withdrawal (11.5\%), and emergency contraception (5.5\%)). In the year 2003, the percentage of South Africans using at least one modern contraceptive was estimated as $60.3 \%$ by the United Nations Statistics Division [9] (2013: 12-13).

A report from the United Nations Children's Fund [10] (2013: 3-8) indicates that 4300 South African mothers die due to complications of pregnancy and childbirth, 20,000 babies are stillborn, 23,000 newborns die in their first month of life, and that 75,000 children die before their fifth birthday. The report points out that $61 \%$ of deaths in children under the age of five years could be linked to failures in the South African health system, and that encouraging mothers in the childbearing age of 15 to 49 years to utilize family planning methods and services effectively is essential for reducing maternal and under-five mortality and morbidity. According to the United Nations Populations Fund [11] (2012: 4-6) and Wilmoth, Zureick, Mizoguchi, Inoue and Oestergaard [12] (2013: 2-3), utilization of modern contraceptives and family planning methods by women in the childbearing age of 15 to 49 years is a critical requirement for the reduction of mortality and morbidity in mothers and children under the age of five years living in the world's least developed countries. Okonta, Ebeigbe and SundayAdeoye [13] (2010: 1087-1090) have found that the most common causes of adverse outcomes of pregnancy among black teenagers are the lack of sex education, the absence of reproductive health services to vulnerable members of the community, poor access to primary health care and family planning services, poverty and unemployment, illiteracy, as well as the lack of counselling services by suitably trained social workers. Miscar- 
riages and abortions often cause the loss of fetus and permanent injury on women. Based on reports issued by the Integrated Regional Information Networks [14] (2013: 4-5) and the Population Council [15] (2013: 2-3), there is a significant association between teenage pregnancy and the spread of sexually transmitted diseases. Perceptions on the advantages and disadvantages of modern family planning methods play a significant role in shaping the attitudes and behavior of sexually active adolescents residing in the CTMM. The prevalence of adverse outcomes of pregnancy depends on the extent to which reproductive health services provided by the CTMM are utilized by sexually active adolescents residing in the city. The study is based on the conceptual framework developed by Wilmoth, Zureick, Mizoguchi, Inoue and Oestergaard [12] (2013: 5-6) in which success in the reduction of adverse outcomes of pregnancy depends on the extent to which reproductive health services and modern family planning methods such as modern contraceptives are effectively utilized by the target population, at the level of individual, program level and community level factors. The South African National Department of Health [16] (2013: 2-6) and the World Bank [17] (2013: 14-15) have both applied significant efforts in terms of promoting the provision of reproductive health and modern family planning services to women of the childbearing age of 15 to 49 years. However, very few studies have been conducted in order to assess the degree to which such services are effectively utilized. Based on data drawn from 40 countries, Ijaiya, Raheem, Olatinwo and Ijaiya [18] (2009: 137-145) have found that there is a statistically significant association between the effective utilization of birth control devices and reduction in adverse outcomes and pregnancy as well as the spread of sexually transmitted diseases and HIV/AIDS in Sub-Saharan African countries including South Africa. This finding is in agreement with findings made by the South African National AIDS Council [19] (2012: 8-13) as well as the United Nations Joint Programme on HIV/AIDS [20] (2012: 11-13) in which the promotion of reproductive health services and modern family planning methods has the potential for reducing the spread of sexually transmitted diseases and HIV/AIDS in Sub-Saharan African countries. The purpose of this particular study is to show that reproductive health services and modern family planning services are not effectively utilized by eligible women living in and around Pretoria, and that adverse outcomes of pregnancy are significantly associated with poor utilization of reproductive health and modern family planning services.

Research questions: the study aims to provide adequate answers to four research questions. The first research question of this study is to identify and quantify key factors that affect adverse pregnancy outcomes and the utilization of modern contraceptives. The second research question is to find out whether or not there is a statistically significant association between underutilization of reproductive health and modern family planning services and adverse outcomes of pregnancy. The fourth and last research question is to find if the degree of utilization of reproductive health and modern family planning services in Pretoria varies by health service delivery wards and health facilities.

\section{Methods and Materials of Study}

\subsection{Study Design and Sample Size of Study}

The design of the study is longitudinal. The study was conducted over a 6-year period between 01 January 2004 and 31 December 2009. The questionnaire of study was filled in by respondents once a year. Data were collected from a total of 8497 women who lived in 2075 households scattered over the four health sub-districts of Pretoria. Women who took part in the study were aged between 15 and 49 years, and lived in four health sub-districts located in and around Pretoria, South Africa. Data were collected on several socio-economic, demographic, health-related and family planning variables by using multi-stage cluster sampling over a 6-year period of study (01 January 2004 and 31 December 2009). Respondents are said to utilize modern family planning methods if they use one or more contraceptive methods such as pills, injection, condoms, sterilization and intra-uterine devices. Sampling frames were provided by Statistics South Africa in Pretoria, South Africa.

\subsection{Statistical Methods of Data Analyses}

Data analyses was performed by using two-by-two Pearson's chi-square tests of associations (Dawson and Trapp [21], 2004: 102-103), binary logistic regression analysis (Hosmer and Lemeshow [22], 2002: 26-28), survival analysis (Cleves, Gould and Gutierrez [23], 2004: 43-45), and multilevel analysis (Snijders and Bosker [24], 1999: 67-72). Pearson's chi-square tests of associations were used for screening influential variables of study from among a large number of variables. For each test of association performed, there were no cells with expected cell frequencies that were below 5 . Binary logistic regression analysis was used for identifying factors that affect utilization of contraceptives. The reliability of the fitted logistic regression model was assessed by using the Hosmer-Lemeshow goodness-of-fit test. Survival analysis was used for identifying factors that affect adverse outcomes of pregnancy. For each influential predictor variable, the constant hazard assumption was verified by using log-minus-log plots. There were no time-varying covariates. The adequacy of the fitted Cox model was as- 
sessed by using the likelihood ratio test and the AIC (Akaike's Information Criterion) as diagnostic procedures. Multilevel analysis was used to test the presence of significant differences among 20 service delivery wards and 11 health facilities with regards to utilization of modern contraceptives.

\section{Results of Study}

Out of the 8497 women who took part in the study, 3, 547 women $(41.74 \%$ of them) utilized at least one modern family planning (FP) method such as contraceptives regularly. The remaining 4950 women (58.26\%) did not utilize any modern family planning method. This estimate of $41.74 \%$ is less than the $52.2 \%$ estimate reported by MacPhail, Pettifor, Pascoe and Rees ([2], 2007: 44-53). The difference in estimates is attributed to the difference in the ages of the two groups of participants. The estimate obtained in this study (41.74\%) is less than those reported by Singh and Darroch ([25], 2012: 11-12) in which the authors have reported relatively higher figures for the years 2008 (56\%) and 2012 (57\%). Based on a national survey conducted by Statistics South Africa ([26], 2012: 23-24), the percentage of married women 15 - 49 years old who were using modern contraceptives in 2010 was $55.1 \%$.

Injections were used by $54.03 \%$ of the 3547 women who were using at least one modern family planning method. Pills were used by $19.6 \%$ of them; Condoms were used by $15.51 \%$ of them; Intrauterine devices were used by $8.20 \%$ of them; Sterilizations were used by $2.37 \%$; Vaginal foams were used by $0.28 \%$ of them. The average age of FP users at first sex was 18.72 years. The average age of FP users at first pregnancy was equal to 19.36 years. The prevalence of teenage pregnancy among the 8497 women in the study was equal to $9.5 \%$. The prevalence of adverse outcomes of pregnancy among the 8497 women in the study was equal to $12.19 \%$. The average number of women in the childbearing age per household varies from 2.4 women in district 1 , to 2.0 women in district 4 , and to 1.5 women in districts 2 and 3 , respectively. The average number of persons per household is 4.1 persons or 1.4 males and 2.7 females respectively.

Some of the 4950 respondents who do not use modern family planning methods have used traditional methods such as withdrawal (1.7\%) and periodic abstinence $(0.12 \%)$. The 3547 respondents who used at least one modern contraceptive method were asked if they were satisfied with their current method, and $86.5 \%$ of them stated that they were satisfied with their method of choice. Roughly $7 \%$ of them stated that they were planning to switch to another method of choice. None of the 3547 FP users in the study showed interest in traditional methods such as withdrawal and periodic abstinence.

The estimates reported above are fairly similar to estimates that were reported by Statistics South Africa [27] (2012: 8-9), the South African National Department of Health [28] (2012: 4-5), the South African National AIDS Council [19] (2012: 6-9), the United Nations Joint Programme on HIV/AIDS [20] (2013: 11-12), the United Nations Children's Fund [10] (2013: 11-12), the United Nations Statistics Division [9] (2013: 5-6), Ijaya, Raheem, Olatinwo and Ijaiya [18] (2009: 137-145), the South African National Department of Health [16] (2013: 8 - 9), and the South African Medical Research Council and ORC MACRO [28] (2007: 12-13). The estimates obtained in this study cannot be compared with those obtained by Seutlwadi, Peltzer, Mchunu and Tutshana [8] (2012: 43-47) in view of the fact that the authors used 3, 123 young men and women aged 18 to 24 years old living in four of the nine provinces in South Africa, whereas this study is based on 3547 women aged 15 to 49 years living in and around Pretoria. The $41.74 \%$ of women who utilized at least one modern contraceptive method are fewer than the $60.3 \%$ of South Africans who used at least one modern contraceptive in 2003 as has been reported by Kaida, Laher, Strathdee, Money, Janssen, Hogg \& Gray [29] (2010: e13868-e13875).

It can be seen from Table 1 that $41 \%$ of FP users and $44.9 \%$ of nonusers were formally married to their sexual partners. The table shows that married women account for the largest percentage of FP users. Women who live together with their sexual partners account for $35.3 \%$ of all FP users. The two groups seem to be fairly similar with regards to experiencing sexually transmitted diseases, ownership of flush toilets, access to tap water at home, and level of trust on sexual partners. FP users seem to be slightly better off than nonusers with regards to average monthly income. The comparisons shown in Table 1 are by and large in agreement with findings obtained from the South African Demographic and Health Survey of 2003 by the South African National Department of Health, the South African Medical Research Council and ORC MACRO [28] (2007: 11-13).

\subsection{Results from Pearson's Chi-Square Tests of Associations}

Table 2 shows that utilization of family planning methods is significantly associated with each of the 16 variables shown in the table. The table shows that contraceptive use is significantly associated with degree of awareness, employment status, level of education and prior history of sexually transmitted diseases. Utilization of modern family planning methods and reproductive health services enables women to better protect themselves from sexually transmitted infectious diseases in- 
Table 1. Comparison between users and nonusers of contraceptives.

\begin{tabular}{|c|c|c|}
\hline Characteristics & Users $(\mathrm{N}=3547)$ & Nonusers $(N=4950)$ \\
\hline \multicolumn{3}{|l|}{ Age distribution } \\
\hline 15 to 24 & $1218(34.34 \%)$ & $1702(34.38 \%)$ \\
\hline 25 to 34 & $1427(40.23 \%)$ & $1992(40.24 \%)$ \\
\hline 35 to 49 & 902 (25.43\%) & $1256(25.37 \%)$ \\
\hline Mean age & 29.6 & 29.3 \\
\hline Median age & 29.4 & 29.2 \\
\hline Average age at first sex & 18.72 & 19.02 \\
\hline Average age at first pregnancy & 19.36 & 18.74 \\
\hline \multicolumn{3}{|l|}{ Level of education } \\
\hline No education & $69(1.9 \%)$ & 195 (3.94\%) \\
\hline Primary & $924(26.1 \%)$ & $2311(46.69 \%)$ \\
\hline Secondary & $2249(63.4 \%)$ & 2175 (43.94\%) \\
\hline Post-secondary & $305(8.6 \%)$ & $269(5.4 \%)$ \\
\hline \multicolumn{3}{|l|}{ Family size } \\
\hline Less than or equal to 5 & $79.84 \%$ & $68.49 \%$ \\
\hline Greater than 5 & $20.16 \%$ & $31.51 \%$ \\
\hline Average number of children living with mother & 1.3 & 1.1 \\
\hline \multicolumn{3}{|l|}{ Number of children living with mother } \\
\hline 0 & $19.6 \%$ & $8.7 \%$ \\
\hline 1 & $14.7 \%$ & $10.1 \%$ \\
\hline 2 & $24.2 \%$ & $28.5 \%$ \\
\hline 3 & $25.8 \%$ & $29.8 \%$ \\
\hline 4 & $11.6 \%$ & $14.6 \%$ \\
\hline 5 or more & $4.1 \%$ & $8.3 \%$ \\
\hline Prevalence of teenage pregnancy & $9.5 \%$ & $10.25 \%$ \\
\hline Prevalence of adverse outcomes of pregnancy & $6.12 \%$ & $16.55 \%$ \\
\hline \multicolumn{3}{|l|}{ Average monthly income in Rand } \\
\hline Less than 1200 Rand & $22.1 \%$ & $27.9 \%$ \\
\hline Between 1201 and 6000 Rand & $51.5 \%$ & $54.4 \%$ \\
\hline Between 6001 and 12,000 Rand & $14.2 \%$ & $9.9 \%$ \\
\hline Between 12,001 and 20,000 Rand & $7.9 \%$ & $6.6 \%$ \\
\hline Greater than 20,000 Rand & $4.3 \%$ & $3.8 \%$ \\
\hline \multicolumn{3}{|l|}{ Marital status } \\
\hline Single or never married & $11.5 \%$ & $18.8 \%$ \\
\hline Married & $41.0 \%$ & $44.9 \%$ \\
\hline Living together & $35.3 \%$ & $26.2 \%$ \\
\hline Separated & $5.0 \%$ & $6.5 \%$ \\
\hline Divorced & $4.4 \%$ & $2.2 \%$ \\
\hline Widowed & $2.8 \%$ & $1.4 \%$ \\
\hline \multicolumn{3}{|l|}{ Employment status } \\
\hline Enrolled students & $27.7 \%$ & $26.4 \%$ \\
\hline Employed & $26.5 \%$ & $16.8 \%$ \\
\hline Not employed & $45.8 \%$ & $56.8 \%$ \\
\hline
\end{tabular}




\section{Continued}

\begin{tabular}{lcc}
\hline Sexually transmitted infectious diseases over the past $\mathbf{1 2}$ months & \\
Not infected & $90.28 \%$ & $90.13 \%$ \\
At least once & $9.72 \%$ & $9.87 \%$ \\
Number of sexual partners over the past $\mathbf{1 2}$ months & & \\
Only one or none & $45.00 \%$ & $43.97 \%$ \\
Two or more & $55.00 \%$ & $56.03 \%$ \\
Access to tap water at home & & \\
Yes & $88.92 \%$ & $87.11 \%$ \\
No & $11.08 \%$ & $12.89 \%$ \\
Ownership of flush toilet at home & & \\
Yes & $57.09 \%$ & $56.33 \%$ \\
No & $42.91 \%$ & $43.67 \%$ \\
Degree of trust on sexual partner & & \\
No trust at all & $4.96 \%$ & $4.01 \%$ \\
Inadequate trust & $8.01 \%$ & $4.85 \%$ \\
Moderate trust & $47.55 \%$ & $52.01 \%$ \\
Good trust & $25.63 \%$ & $24.68 \%$ \\
Absolute trust & $13.85 \%$ & $14.45 \%$ \\
\hline
\end{tabular}

Table 2. Results from the Pearson chi-square tests of associations.

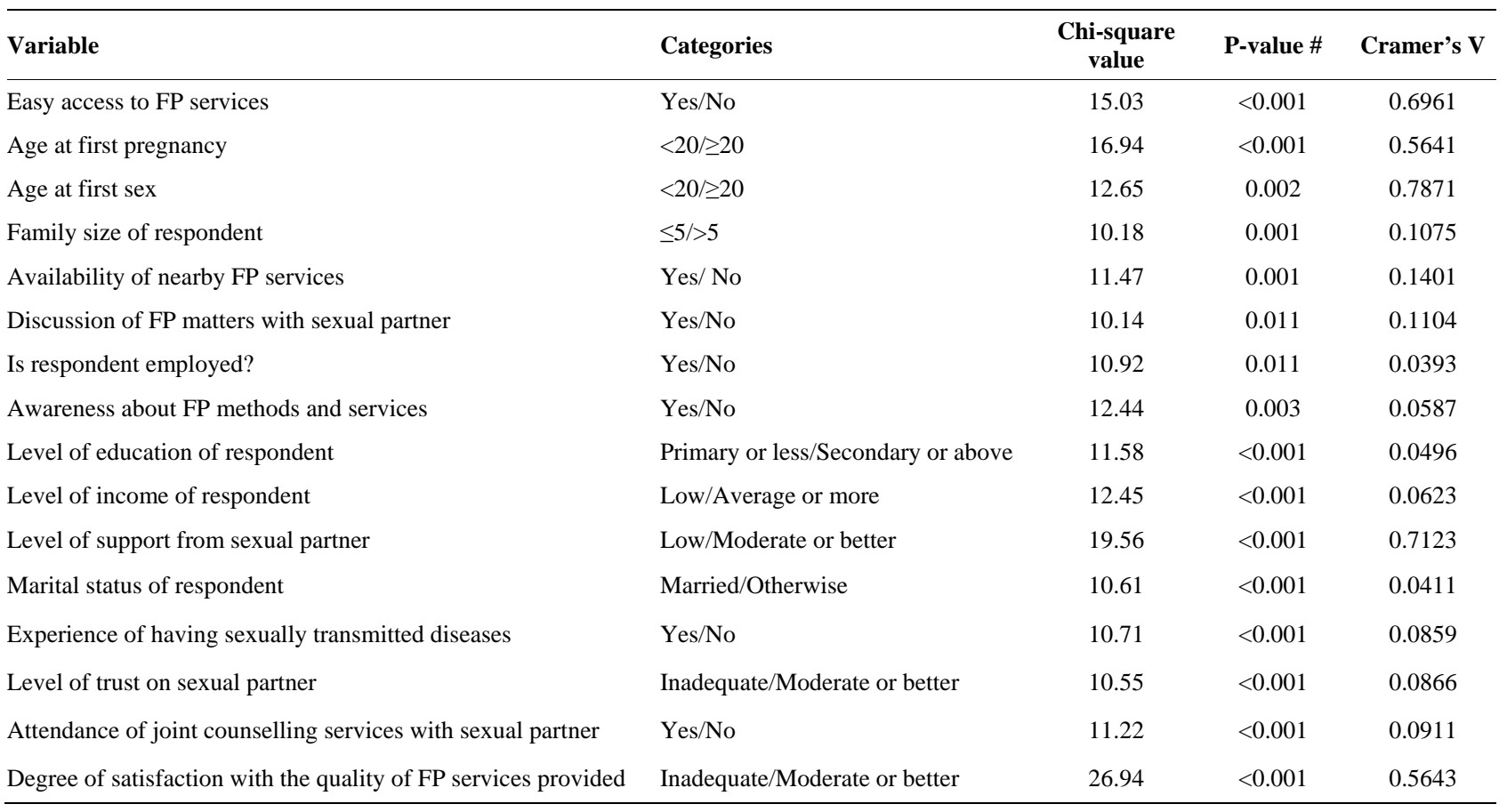

${ }^{\#}$ Significance $=\mathrm{P}<0.05$.

cluding HIV/AIDS. The study conducted in Soweto, South Africa by Kaida, Laher, Strathdee, Money, Janssen, Hogg and Gray [29] (2010: e13868-e13875) has found that there is a statistically significant association between HIV status and use of modern contraceptives. The study showed that $78 \%$ of women who were free from HIV utilized modern family planning and reproductive health services, and that women who were not utilizing reproductive health services were 2.40 times more likely to fall victim to HIV in comparison with women who utilized the services. A similar finding has been reported by researchers in Uganda. Based on a clinical trial con- 
ducted in Uganda, Hladik, Stover, Esiru, Harper and Tappero [30] (2009: e7691-e7699) have found that utilization of family planning services to women substantially lowers the risk of transmission of HIV from pregnant mothers to their children.

\subsection{Results from Binary Logistic Regression Analysis}

The aim of performing binary logistic regression analysis was to identify and quantify key factors that affect utilization of modern family planning services and contraceptives. Table 3, below, shows odds ratios estimated from binary logistic regression analysis under the random effects model. The table shows that 8 of the 16 variables used for analysis were significant at the $5 \%$ level of sig-

Table 3. Estimates obtained from logistic regression analysis with random effects.

\begin{tabular}{|c|c|c|c|}
\hline Characteristic & $\begin{array}{l}{ }^{*} \text { Adjusted } \\
\text { Odds Ratio }\end{array}$ & P-value & 95\% C.I. \\
\hline \multicolumn{4}{|l|}{ Access to FP services } \\
\hline Yes (r) & 1.00 & & \\
\hline No & 4.59 & $<0.001^{* * *}$ & $(2.18,7.38)$ \\
\hline \multicolumn{4}{|c|}{ Support from sexual partner } \\
\hline Yes (r) & 1.00 & & \\
\hline No & 4.51 & $<0.001^{* * *}$ & $(2.14,7.16)$ \\
\hline \multicolumn{4}{|l|}{ Age at first pregnancy } \\
\hline 20 years or above $(\mathrm{r})$ & 1.00 & & \\
\hline Less than 20 years & 3.08 & $<0.001^{* * *}$ & $(2.04,6.88)$ \\
\hline \multicolumn{4}{|l|}{ Counselling services } \\
\hline Yes (r) & 1.00 & & \\
\hline No & 3.03 & $0.001^{* * *}$ & $(2.03,6.88)$ \\
\hline \multicolumn{4}{|l|}{ Family size } \\
\hline$\leq 5(\mathrm{r})$ & 1.00 & & \\
\hline$>5$ & 2.89 & $0.001^{* * *}$ & $(1.98,6.57)$ \\
\hline \multicolumn{4}{|l|}{ Nearby FP services } \\
\hline Yes (r) & 1.00 & & \\
\hline No & 2.91 & $0.002^{* * *}$ & $(1.99,6.59)$ \\
\hline \multicolumn{4}{|l|}{ Discussion of FP matters } \\
\hline Yes (r) & 1.00 & & \\
\hline No & 2.79 & $0.004^{* * *}$ & $(1.75,6.11)$ \\
\hline \multicolumn{4}{|c|}{ Satisfaction with FP services } \\
\hline Total satisfaction (r) & 1.00 & & \\
\hline No satisfaction at all & 4.45 & $<0.000^{* * *}$ & $(2.12,7.03)$ \\
\hline Inadequate satisfaction & 3.09 & $0.001^{* * *}$ & $(2.06,6.96)$ \\
\hline Moderate satisfaction & 1.54 & $0.046^{*}$ & $(1.13,4.83)$ \\
\hline Good satisfaction & 1.09 & $0.049^{*}$ & $(1.09,4.51)$ \\
\hline
\end{tabular}

*Adjustment was done for religion, level of income, level of education and employment status. nificance. The random effects binary logistic regression model gave an Intra Class Coefficient (rho) of $0.8937=$ $89.37 \%$, showing that individual women in the same group resembled each other fairly well.

The Odds Ratios (OR) estimated from binary logistic regression analysis show that utilization of contraceptives was significantly influenced by 4 factors. These factors were: easy access to family planning services, level of support from sexual partner, and young age at first pregnancy, in a decreasing order of strength. These findings are in agreement with findings obtained from the South African Demographic and Health Survey of 2003 by the South African National Department of Health, the South African Medical Research Council and ORC MACRO [28] (2007: 14-15), and Seutlwadi, Peltzer, Mchunu and Tutshana [8] (2012: 43-47). The results are also in agreement with figures reported by the United Nations Populations Fund [11] (2012: 8-9), Williamson, Parkes, Wight, Petticrew and Hart [31] (2009: 1-12), the World Health organization (2009), the WHO/UNAIDS/ UNICEF [32] (2012: 5-6), and Johnson, Coetzee and Dorrington [33] (2005: 287-293).

The odds ratio of the variable access to family planning services is 4.59 . This shows that a woman who does not have easy access to family planning services is 4.59 times as likely not to utilize family planning services in comparison with another woman who has easy access to family planning services. The odds ratio of the variable support is 4.51 . This shows that a woman who has no support from her sexual partner in terms of utilizing family planning services is 4.51 times as likely not to utilize family planning services in comparison with another woman who enjoys support for doing so from her sexual partner. The odds ratio of the variable age at first pregnancy is 3.08. This shows that a woman whose age at first pregnancy is below 20 years is 3.08 times as likely not to utilize family planning services in comparison with another woman whose age at first pregnancy is 20 years or above. The odds ratio of the variable counselling services is 3.03 . This shows that a woman who does not attend joint counselling services on family planning services with her sexual partner is 3.03 times as likely not to utilize family planning services in comparison with another woman who attends joint counselling services on family planning services with her sexual partner. The odds ratio of the variable family size is 2.89 . This shows that a woman whose family size is larger than 5 is 2.89 times as likely not to utilize family planning services in comparison with another woman whose family size is less than or equal to 5 . The odds ratio of the variable nearby family planning services is 2.91 . This shows that a woman who has no access to nearby family planning services is 2.91 times as likely not to utilize family planning services in comparison with another woman who 
enjoys nearby family planning services. The odds ratio of the variable discussion of FP matters is 2.79. This shows that a woman who is unable to discuss family planning matters freely with her sexual partner is 2.79 times as likely not to utilize family planning services in comparison with another woman who can do so. The variable satisfaction with FP services has 5 categories, and is significant. Adjustment was done for four potential confounding variables: religion, level of income, level of education, and employment status. Unadjusted and adjusted odds ratios did not differ much. This shows that none of the four variables used for adjustment was a confounding or effect modifying variable.

\subsection{Results from Survival Analysis}

The aim of survival analysis was to identify factors that significantly affect the occurrence of an adverse outcome of pregnancy among women in the childbearing age category of 15 to 49 years. Analysis was done by using the Cox proportional hazards model as outlined by Cleves, Gould \& Gutierrez [23] (2004: 58-61). Hazard ratios, as defined by Greene [34] (2003: 43-45), were used as an econometric measure of effect for identifying and quantifying key predictors of adverse outcomes of pregnancy. At the 5\% level of significance, influential predictors of an adverse outcome of pregnancy are characterized by hazard ratios that differ from 1 significantly, 95\% confidence intervals of hazard ratios that do not contain 1 , and P-values that are smaller than 0.05 . Table 4 provides a comparison between women who experienced adverse outcomes of pregnancy with those who did not experience adverse outcomes of pregnancy with regards to factors related to the utilization of modern family planning services and socioeconomic status. In the 6-year long period of study, 1036 of the 8497 women who took part in the study (12.19\%) experienced at least one adverse outcome of pregnancy. The other 7461 women (87.81\%) did not experience any adverse outcome of study during the study period. In survival analysis, the phrase "Non-survivors" represents the 1036 women who experienced at least one adverse outcome of pregnancy in the study period. The phrase "Survivors" represents the 7461 women who did not experience any adverse outcome of pregnancy in the study period. Out of the 1 , 036 women who experienced adverse outcomes of pregnancy, 819 (79.05\%) were nonusers of family planning methods whereas 217 of them (20.95\%) were users of family planning methods.

Table 4 shows that women who experienced at least one adverse outcome of pregnancy during the 6-year long study period were significantly different from those who did not experience any adverse outcome of pregnancy with regards to the variables of comparison. It can
Table 4. Group proportions with regards to adverse outcomes of pregnancy.

\begin{tabular}{|c|c|c|}
\hline Predictor variable & $\begin{array}{l}\text { No adverse outcomes } \\
(\mathrm{N}=7461)\end{array}$ & $\begin{array}{l}\text { Adverse outcomes } \\
(\mathrm{N}=1036)\end{array}$ \\
\hline Access to FP services & $\begin{array}{l}\text { Yes: } 54 \% \\
\text { No: } 46 \%\end{array}$ & $\begin{array}{l}\text { Yes: } 24 \% \\
\text { No: } 76 \%\end{array}$ \\
\hline Unwanted pregnancy & $\begin{array}{l}\text { Yes: } 13 \% \\
\text { No: } 87 \%\end{array}$ & $\begin{array}{l}\text { Yes: } 79 \% \\
\text { No: } 21 \%\end{array}$ \\
\hline Age at first pregnancy & $\begin{array}{l}13 \text { to } 19: 39 \% \\
20 \text { or above: } 61 \%\end{array}$ & $\begin{array}{l}13 \text { to } 19: 77 \% \\
20 \text { or above: } 23 \%\end{array}$ \\
\hline Utilization of FP services & $\begin{array}{l}\text { Yes: } 36 \% \\
\text { No: } 64 \%\end{array}$ & $\begin{array}{l}\text { Yes: } 11 \% \\
\text { No: } 89 \%\end{array}$ \\
\hline $\begin{array}{l}\text { Discussion of FP matters } \\
\text { with sexual partner }\end{array}$ & $\begin{array}{l}\text { Yes: } 29 \% \\
\text { No: } 71 \%\end{array}$ & $\begin{array}{l}\text { Yes: } 2 \% \\
\text { No: } 98 \%\end{array}$ \\
\hline Family size & $\begin{array}{l}\leq 5: 58 \% \\
<5: 42 \%\end{array}$ & $\begin{array}{l}\leq 5: 29 \% \\
<5: 71 \%\end{array}$ \\
\hline Nearby FP services & $\begin{array}{l}\text { Yes: } 58 \% \\
\text { No: } 42 \%\end{array}$ & $\begin{array}{l}\text { Yes: } 32 \% \\
\text { No: } 68 \%\end{array}$ \\
\hline Average monthly income & $\begin{array}{l}\text { Very low }(14 \%) \\
\text { Low }(21 \%) \\
\text { Average (39\%) } \\
\text { Above average (19\%) } \\
\text { High }(7 \%)\end{array}$ & $\begin{array}{l}\text { Very low (29\%) } \\
\text { Low (43\%) } \\
\text { Average (34\%) } \\
\text { Above average (3\%) } \\
\text { High (1\%) }\end{array}$ \\
\hline Highest level of education & $\begin{array}{l}\text { No education: } 8 \% \\
\text { Primary: } 11 \% \\
\text { Secondary: } 58 \% \\
\text { Post-secondary: } 23 \%\end{array}$ & $\begin{array}{l}\text { No education: } 15 \% \\
\text { Primary: } 29 \% \\
\text { Secondary: } 52 \% \\
\text { Post-secondary: } 4 \%\end{array}$ \\
\hline Employment & $\begin{array}{l}\text { Yes: } 31 \% \\
\text { No: } 69 \%\end{array}$ & $\begin{array}{l}\text { Yes: } 8 \% \\
\text { No: } 92 \%\end{array}$ \\
\hline
\end{tabular}

be seen from the table that "non-survivors" or women who have experienced at least one adverse outcome of pregnancy are characterized by lack of easy access to modern family planning services, poor utilization of family planning services, inability to discuss family planning matters with their sexual partners, large family sizes, unwanted pregnancies, young age (teenagers during their first pregnancies), low monthly income, low level of education, and unemployment. The key finding of this analysis is that women who experienced adverse outcomes of pregnancy were characterized by poor utilization of reproductive health and modern family planning services. This key finding of study is consistent with findings obtained from the South African Demographic and Health Survey of 2003 by the South African National Department of Health [16] (2013: 3-5), Statistics South Africa [26] (2012: 8-11), the South African Medical Research Council and ORC MACRO [28] (2007: 12-13) and Seutlwadi, Peltzer, Mchunu and Tutshana [8] (2012: 43-47).

Kaplan-Meier survival probability plots were used for comparing the survival probabilities of women with regards to utilization of modern family planning methods such as contraceptives. The plot shown in Figure 1 shows that women who used modern contraceptives (FP use) have a relatively larger probability of survival or fewer adverse outcomes of pregnancy in comparison 


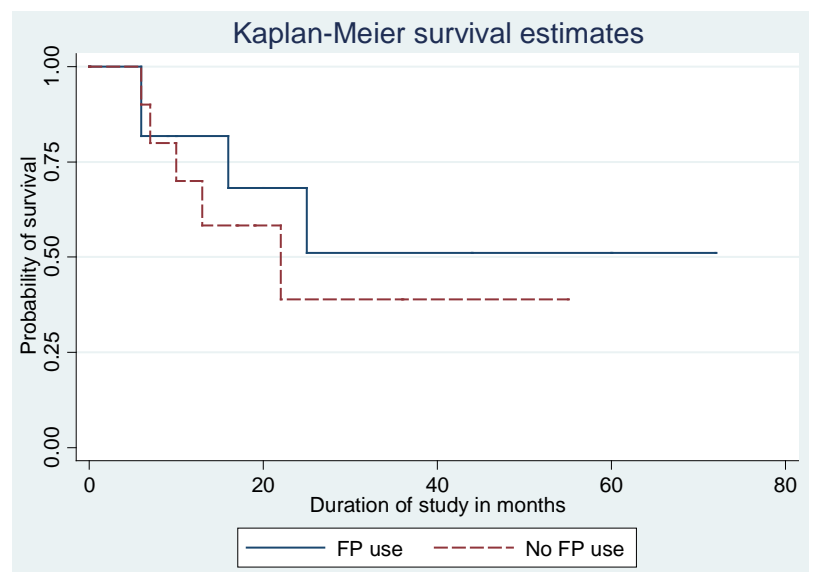

Figure 1. Kaplan-Meier survival estimates, by utilization of family planning methods.

with women who did not use modern family planning services such as contraceptives (no FP use).

Table 5 shows hazard ratios estimated from Cox regression. The table shows that occurrence of an adverse outcome of pregnancy was most strongly influenced by 6 of the 12 predictor variables used for survival analysis. These 6 influential predictor variables were: access to family planning services, unwanted pregnancy, age at first pregnancy, utilization of family planning services, family size and availability of nearby family planning services, in a decreasing order of influence. These findings are consistent with what has been found for the majority of Sub-Saharan African countries by WHO/UNAIDS/UNICEF [32] (2012: 8-11), the United Nations Statistics Division [9] (2012: 7-10) and the United Nations Population Fund [35] (2005: 8-11). The top three predictors of maternal mortality identified in the study conducted by Wilmoth, Zureick, Mizoguchi, Inoue and Oestergaard [12] (2012: 3-5) are fairly similar to the key predictors that affect adverse outcomes of pregnancy in this study (lack of easy access to family planning services, unwanted pregnancy, and young age at first pregnancy).

The hazard ratio of the variable access to family planning services is 4.02 . This shows that a woman who does not have easy access to family planning services is 4.02 times as likely to experience an adverse outcome of pregnancy in comparison with another woman who has easy access to family planning services. The hazard ratio of the variable unwanted pregnancy is 3.79. This shows that a woman who becomes pregnant without being prepared for the challenge is 3.79 times as likely to experience an adverse outcome of pregnancy in comparison with another woman who becomes pregnant out of her own good will. The hazard ratio of the variable age at first pregnancy is 2.89 . This shows that a woman whose age at first pregnancy is below 20 years is 2.89 times as likely to experience an adverse outcome of pregnancy in comparison with another woman whose age at first pregnancy is 20 years or above. The hazard ratio of the variable utilization of family planning services is 2.84 . This shows that a woman who does not utilize family planning services regularly is 2.84 times as likely to experience an adverse outcome of pregnancy in comparison with another woman who utilizes family planning services regularly. The hazard ratio of the variable family size is 2.83. This shows that a woman whose family size is larger than 5 is 2.83 times as likely to experience an adverse outcome of pregnancy in comparison with another woman whose family size is less than or equal to 5 . The hazard ratio of the variable nearby family planning services is 2.79. This shows that a woman who has no access to nearby family planning services is 2.79 times as likely to experience an adverse outcome of pregnancy in comparison with another woman who enjoys nearby family planning services. Adjustment was done for three potential confounding variables: sub-district, employment status and level of education. Unadjusted and adjusted hazard ratios did not differ much. This shows that none of the three variables used for adjustment was a confounding or effect modifying variable.

The results obtained from Cox regression are fairly similar to those obtained from Pearson's chi-square tests of association, log-linear analysis as has been outlined by Agresti [36] (2002: 43-45), logit regression, probit regression, the log-rank test, Cox regression, Weibull regression and log-normal regression as has been outlined by Verbeek [37] (2000: 41-44). In each of the methods used, the appropriate measures of effect have been used for identifying influential predictor variables. According to Verbeek [37] (2000: 41-44), hazard ratios estimated based on longitudinal studies are theoretically the most reliable measures of effect in impact studies.

\subsection{Results from Multilevel Analysis}

Based on findings from multilevel analysis, contraceptive use varied significantly from ward to ward (20 service delivery wards) as well as from facility to facility (11 service delivery facilities). The difference among the 20 service delivery wards accounted for $12.49 \%$ of total variation in the quality of services delivered to women of the childbearing age of 15 to 49 years of age. The difference among the 11 health service facilities accounted for $13.52 \%$ of total variation in the quality of services delivered to women of the childbearing age of 15 to 49 years of age. Health facilities and wards jointly accounted for $26.01 \%$ of the total variation. Facilities nested within the same wards were significantly different (48\%) from each other. This shows that health facilities were not homogeneous in nature, and that it did matter which health facility women went to in order to receive family planning services. This finding clearly shows that services at 
Table 5. Adjusted hazard ratios from the Cox Proportional Hazards Model.

\begin{tabular}{cccc}
\hline Variable & ${ }^{*}$ Adjusted Hazard Ratio & P-value & 95\% CI \\
\hline Access to FP services & 4.02 & $<0.001$ & $(2.13,6.59)$ \\
Unwanted pregnancy & 3.79 & 0.001 & $(1.24,5.69)$ \\
Age at first pregnancy & 2.89 & 0.003 & $(1.19,4.22)$ \\
Utilization of FP services & 2.84 & 0.004 & $(1.14,4.18)$ \\
Family size & 2.83 & 0.005 & $(1.13,4.17)$ \\
Nearby FP services & 2.79 & 0.007 & $(1.11,4.14)$ \\
\hline
\end{tabular}

*Adjustment was done for level of income, level of education and employment status.

the level of facilities were not standardized adequately. That is, some facilities were doing much better than others although all facilities are supposed to be equally efficient in terms of service delivery. For example, health facilities rendering family planning services in predominantly white suburbs were significantly better equipped and well resourced in comparison with facilities rendering services in predominantly black suburbs such as Mamelodi. Intervention is required by the CTMM to address this challenge. Finally, results obtained from multilevel analysis show that women receiving family planning services within the same health facilities shared similar characteristics with each other. Similar findings have been reported for other Sub-Saharan African countries by the United Nations Populations Fund [35] (2012: 6-7), the United Nations Children's Fund [10] (2013: 4-6), the World Bank [36] (2011: 11-14) and Hayes [5] (2012: 49.e1-49.e9). The study conducted by Williamson, Parkes, Wight, Petticrew and Hart [31] (2009: 1-12) in five developing countries has found that vital reproductive health and modern family planning services in developing countries are often underutilized by women in the childbearing age of 15 to 49 years mostly due to limited knowledge, lack of access, worries about fertility and the low status of women. This finding is consistent with reports issued by the World Health Organization [36] (2009: 4-6).

\section{Key Findings and Discussion of Results}

\subsection{Strong Points of Study}

This is one of very few studies conducted in South Africa based on a longitudinal study design. The study has established a comprehensive database that could be used for estimating badly needed statistical figures by health and family planning practitioners in South Africa. The longitudinal nature of the study has enabled South African researchers to estimate hazard ratios from the Cox Proportional Hazards Model, and these hazard ratios have been used for estimating the key predictors of adverse outcomes of pregnancy among women in the childbearing age of 15 to 49 years. The size of the sam- ple is also much larger than the sizes of previous studies conducted in South Africa. Hazard ratios are a much more robust epidemiological measure of effect in comparison with odds ratios. As such, findings of this study have the potential for assisting health planners and professionals who are responsible for the provision of reproductive health and family planning services to women who live in Sub-Saharan African countries including South Africa. Based on findings from multilevel analysis, contraceptive use varied significantly from ward to ward as well as from facility to facility. This fact shows that health facilities were not homogeneous in nature, and that it did matter which health facility women went to in order to receive family planning services. This finding clearly shows that services at the level of facilities were not standardized adequately. That is, some facilities were doing much better than others although all facilities are supposed to be equally efficient in terms of service delivery. For example, health facilities rendering family planning services in predominantly white suburbs were significantly better equipped and well resourced in comparison with facilities rendering services in predominantly black suburbs such as Mamelodi. Intervention is required by the CTMM to address this inequality. Results obtained from multilevel analysis show that women receiving family planning services within the same health facilities shared similar characteristics with each other. The study has shown that unwanted pregnancy and adverse pregnancy outcomes among poor black women constitute a major health problem in and around the City of Pretoria, South Africa.

The study has shown that utilization of modern family planning methods and reproductive health services is vital in curbing the spread of sexually transmitted infectious diseases including HIV/AIDS. This finding is similar to findings reported by Kaida, Laher, Strathdee, Money, Janssen, Hogg and Gray [29] (2010) based on a study conducted in Soweto, South Africa. A similar finding has been reported by researchers in Uganda. Based on a clinical trial conducted in Uganda, Hladik, Stover, Esiru, Harper and Tappero [30] (2009) have found that utilization of family planning services to women sub- 
stantially lowers the risk of transmission of HIV from pregnant mothers to their children. According to Johnson, Coetzee and Dorrington [33] (2005: 287-293), the prevalence of STIs in South Africa is high, although there is an extensive variability between regions. The seroprevalence of syphilis (Treponema pallidum) is typically around $10 \%$ in women attending antenatal and family planning clinics. Prevalence rates are significantly higher in "high risk" groups such as sex workers and men with urethritis (24\% - 42\%).

The study has shown that the provision of vital reproductive health and modern family planning services is undermined due to a lack of service delivery and performance at the level of health service delivery wards (12.49\%) and health service facilities (26.01\%). These findings make intervention easy. There is a dire need for the promotion of community based family planning services specifically aimed at poor women with ages 15 to 49 years. While it is true that community based clinics are the most efficient health service centers for promoting the use of modern contraceptives and family planning methods, the facilities are underutilized in comparison with hospitals and private sector service providers.

\subsection{Limitation of Study}

The study had to be discontinued at the end of 2009 due to shortage of funding. It would be valuable for the South African National Department of Health to extend metropolitan municipalities such as Johannesburg, Cape Town and Durban in order to obtain comparative estimates.

\subsection{Implications of Study and Recommendations}

The study has shown that reproductive health and modern family planning services that are provided to women living in and around the City of Pretoria were utilized by only $41.74 \%$ of eligible women, and that women who experienced adverse outcomes of pregnancy were characterized by failure to utilize modern family planning services effectively. The study has also shown that there was a significant difference among the 20 health service delivery wards and 11 health service facilities in which reproductive health services were delivered to women with regards to the quality of service delivery. According to Statistics South Africa [27] (2012: 12-13), the percentage of married women of 15 - 49 years old who were using modern contraceptives in 2010 was only $55.1 \%$. At the present pace, South Africa will not achieve Target number 7 of Goal number 6 of the Millennium Development Goals by the year 2015 in view of the fact that $44.9 \%$ of women in the childbearing age of 15 to 49 years do not have access to modern family planning services and contraceptives. The vast majority of women who have no access to modern family planning and re- productive health services are black, poor, rural, unemployed and poorly educated. The implications of the study require that the following measures should be taken by the Health Department of the City of Tshwane Metropolitan Municipality (CTMM) in order to realize the effective utilization of reproductive health and family planning services and to reduce the prevalence of adverse outcomes of pregnancy:

- Efforts must be made to reduce adverse pregnancy outcomes and teenage pregnancy in District 4 (mostly black and unemployed women). This recommendation is consistent with recommendations made by the WHO/UNAIDS/UNICEF [32] (2013) to Sub-Saharan African countries including South Africa.

- Improved modern family planning and reproductive health services must be provided to women living in health sub-district 4 .

- Health education on safe sex practice, abstinence as well as the use of modern family planning methods should be provided to all youth aged 15 to 19 living in and around the City of Pretoria. There should be a fully fledged and well-resourced counselling service targeting the youth.

- The quality of family planning services provided at the 20 service delivery wards and 11 health facilities must be standardized.

- According to the World Bank [38] (2011: 21-23), empirical evidence is essential for the optimal allocation of scarce resources that are required for efficient service delivery. A community-based approach should be followed to implement a monitoring and evaluation programme with a view to monitor and assess efficiency in service delivery. Such a monitoring and evaluation programme would enable the collection of statistical data and empirical evidence on key indicators that are integral to all family planning and reproductive health services that are being delivered by the CTMM to women in the childbearing age of 15 to 49 years. Such data sets could be systematically stored and analyzed for the purpose of producing vital reports for decision making and planning by the CTMM. The data sets would also promote research efforts by the CTMM significantly, and enable the CTMM to collaborate with academic and research institutions on research-related matters and advocacy. This recommendation is in line with the recommendations made by the World Health Organization for Sub-Saharan African countries [39] (2011).

- Health education on optimal family size plus incentives should be given to parents in District 4. This recommendation is in line with the recommendation made by the South African Presidency [40] (2009), recommendations made by the World Bank for SubSaharan African countries (2009). 
- It is highly recommended that a similar study should be conducted once in five years with a view to produce reliable estimates on key performance monitoring indicators that are relevant to the provision of family planning services by the CTMM to the general population living in and around Pretoria. This is crucially important for all impact evaluation studies that are planned by researchers working for the CTMM.

\section{REFERENCES}

[1] City of Tshwane Metropolitan Municipality, "Annual Report for 2011/2012,” 2013.

http://www.tshwane.gov.za/documents/healthcare/Annual $\underline{\text { Report }}$

[2] C. MacPhail, A. E. Pettifor, S. Pascoe and H. V. Rees, "Contraception Use and Pregnancy among 15 - 24 Year Old South African Women: A Nationally Representative Cross-Sectional Survey,” BMC Medicine, Vol. 5, No. 1, 2007, pp. 44-53.

http://dx.doi.org/10.1186/1741-7015-5-31

[3] Z. Mofono, “Teenage Contraceptive Needs in Urban South Africa: A Case Study,” International Family Planning Perspectives, Vol. 24, No. 4, 1998, pp. 180-183. http://dx.doi.org/10.2307/2991977

[4] South African Government Communication and Information System (GCIS), "White Paper on Population Policy 1998,” 1998. http://www.info.gov.za/view/

[5] R. M. Hayes, "Maternal Antidepressant Use and Adverse Outcomes: A Cohort Study of 228,876 Pregnancies,” American Journal of Obstetrics \& Gynecology, Vol. 207, No. 1, 2012, pp. 49.e1-49.e9.

[6] South African Government Communication and Information System (GCIS), "The Choice on Termination of Pregnancy Act of South Africa 1996,” 1996. http://www.info.gov.za/acts/1996/

[7] R. Jewkes, H. Brown, K. Dickson-Tetteh, J. Levin and H. Rees, "Prevalence of Morbidity Associated with Abortion before and after Legalization in South Africa," British Medical Journal, Vol. 324, No. 7348, 2002, pp. 1252-1263. http://dx.doi.org/10.1136/bmj.324.7348.1252

[8] L. Seutlwadi, K. Peltzer, G. Mchunu and B. O. Tutshana, "Contraceptive Use and Associated Factors among South African Youth (18 - 24 Years): A Population-Based Survey," South African Journal of Obstetrics and Gynecology, Vol. 18, No. 2, 2012, pp. 43-47.

[9] United Nations Statistics Division, "Millennium Development Goals Indicators for 2012,” 2013. http://mdgs.un.org/unsd/mdg/Default.aspx

[10] United Nations Children's Fund, "Mother and Child Healthcare,” 2013. http://www.unicef.org/southafrica/survival_devlop_759.h $\underline{\mathrm{tml}}$

[11] United Nations Population Fund, "Family Planning: So that Every Pregnancy Is Wanted,” 2012. http://www.unfpa.org/rh/planning.htm

[12] J. Wilmoth, S. Zureick, N. Mizoguchi, M. Inoue and M.
Oestergaard, "Levels and Trends of Maternal Mortality in the World for 2012: The Development of New Estimates by the United Nations," Technical Report Submitted to the WHO, UNICEF, UNFPA and the World Bank, 2013. http://www.who.int/reproductivehealth/publications/

[13] P. I. Okonta, P. N. Ebeigbe and I. Sunday-Adeoye, "Liberalization of Abortion and Reduction of Abortion Related Morbidity and Mortality in Nigeria," Acta Obstetricia et Gynecologica Scandinavica, Vol. 89, No. 8, 2010, pp. 1087-1090. http://dx.doi.org/10.3109/00016341003801649

[14] Integrated Regional Information Networks, "South Africa: Hospitals Failing to Treat HIV-Positive Infants,” 2013. http://www.plusnews.org/

[15] Population Council, “Access to Contraceptive Methods," 2013. http://www.popcouncil.org/topics/

[16] South African National Department of Health, "The South African Antiretroviral Treatment Guidelines: A Joint Report by the Department of Health and SANAC," 2013. www.avert.org/aidssouthafrica.htm

[17] World Bank, "Report by the Independent Evaluations Group of the World Bank on Development Indicators for 2012," 2013. http://www.worldbank.org/ieg/

[18] G. T. Ijaiya, U. A. Raheem, A. O. Olatinwo and M. A. Ijaiya, "Estimating the Impact of Birth Control on Fertility Rate in Sub-Saharan Africa," African Journal of Reproductive Health, Vol. 13, No. 4, 2009, pp. 137-145.

[19] South African National AIDS Council, "Media Statement of 25 March 2010: Outline of the National HIV Counselling and Testing (HCT) Campaign by Dr. Aaron Motsoaledi, Minister of Health,” 2012. http://www.sanac.org.za/files/uploaded/media\%20Statem ent

[20] United Nations Joint Programme on HIV/AIDS, "Global AIDS Response Progress Report for 2012,” 2013. http://www.unaids.org/en/dataanalysis/knowyourresponse/

[21] A. Dawson and R. G. Trapp, "Basic and Clinical Biostatistics,” 4th Edition, McGraw Hill, New York, 2004.

[22] W. Hosmer and S. Lemeshow, “Applied Logistic Regression,” John Wiley \& Sons, New York, 2002.

[23] M. Cleves, W. Gould and R. Gutierrez, "An Introduction of Survival Analysis Using STATA,” Revised Edition, STATA Press, Houston, 2004.

[24] T. A. Snijders and R. J. Bosker, "Multilevel Analysis: An Introduction to Basic and Advanced Multilevel Modelling," SAGE, New York, 1999.

[25] S. Singh and J. E. Darroch, “Adding It Up: Costs and Benefits of Contraceptive Services-Estimates for 2012,” Guttmacher Institute and United Nations Population Fund, New York, 2012.

[26] Statistics South Africa, "Fast Facts," Statistics South Africa, Pretoria, 2012.

[27] Statistics South Africa, "Millennium Development Goals for South Africa: Country Report 2010,” 2011.

http://www.statssa.gov.za/news_archive/docs/mdgr_2010 .pdf

[28] South African National Department of Health, South Afri- 
can Medical Research Council and ORC MACRO, "Results from South Africa Demographic and Health Survey of 2003,” South African National Department of Health, Pretoria, 2007.

[29] A. Kaida, F. Laher, S. A. Strathdee, D. Money, P. A. Janssen, R. S. Hogg and G. Gray, "Contraceptive Use and Method Preference among Women in Soweto, South Africa: The Influence of Expanding Access to HIV Care and Treatment Services,” PloS One, Vol. 5, No. 11, 2010, pp. e13868-e13875. http://dx.doi.org/10.1371/journal.pone.0013868

[30] W. Hladik, J. Stover, G. Esiru, M. Harper and J. Tappero, "The Contribution of Family Planning towards the Prevention of Vertical HIV Transmission in Uganda," PLoS One, Vol. 4, No. 1, 2012, pp. e7691-e7699.

[31] L. M. Williamson, A. Parkes, D. Wight, M. Petticrew and G. J. Hart, "Limits to Modern Contraceptive Use among Young Women in Developing Countries: A Systematic Review of Qualitative Research," Reproductive Health Journal, Vol. 6, No. 3, 2009, pp. 1-12.

[32] WHO/UNAIDS/UNICEF, “Towards Universal Access: Scaling up Priority HIV/AIDS Interventions in the Health Sector,” 2013. http://www.who.int/hiv/pub/2012

[33] L. Johnson, D. Coetzee and R. Dorrington, "Sentinel Surveillance of Sexually Transmitted Infections in South Africa: A Review," Sexually Transmitted Infections, Vol.
81, No. 4, 2005, pp. 287-293.

http://dx.doi.org/10.1136/sti.2004.013904

[34] W. H. Greene, "Econometric Analysis," 5th Edition, Prentice Hall, New York, 2003.

[35] United Nations Population Fund, "State of the World Population for 2004: The Cairo Consensus at Ten, Population, Reproductive Health and the Global Effort to End Poverty,” 2005. http://www.unfpa.org/public/icpd/pid/5093

[36] A. Agresti, "Categorical Data Analysis," 2nd Edition, John Wiley and Sons, New York, 2002. http://dx.doi.org/10.1002/0471249688

[37] M. Verbeek, “A Guide to Modern Econometrics,” John Willey and Sons, New York, 2000.

[38] World Bank, “Annual Report for 2010,” 2011. http://web.worldbank.org/website/external/

[39] World Health Organization, "Making Pregnancy Safer: Annual Report for 2008,” 2009. http://whqlibdoc.who.int/hq/2009/WHO_MPS_09.09_eng .pdf

[40] South African Presidency, “Address by President Jacob Zuma on the Occasion of World AIDS Day at the Pretoria Showground," 2009. www.info.gov.za/speeches/2009/09120112151001.htm 